\title{
Changing Organic Matter Characteristics of Littoral Sediment by Solar Cell-Combined Sediment Microbial Fuel Cell
}

\author{
Narong Touch, Hiroki Takata, Satoshi Yamaji, and Tadashi Hibino
}

\begin{abstract}
Metal ion or clay mineral-adsorbed organic matter present in littoral sediment is known as hardly decomposed organic matter, which is difficult to use as a natural resource. This study is aimed at changing the organic matter characteristics of littoral sediment through the application of solar cell-combined sediment microbial fuel cell (SC-SMFC). The experimental results showed that the sediment pH decreases and the concentration of metal ions in the sediment pore water increases after the application of SC-SMFC. This suggests the dissociation of metal complexes in the sediment. From the analysis results of organic matter characteristics, variations in the ignition characteristics of the sediment and the absorbance at wave number ranges of $3300-3800$ and $800-1800 \mathrm{~cm}^{-1}$ were confirmed, indicating changes in organic matter characteristics of the sediment. It can be concluded that SC-SMFC can separate organic matter from metal complexes, leading to the transformation of organic matter in sediment from valueless into a useful product.
\end{abstract}

Index Terms-Dissociation, metal complex, sediment microbial fuel cell, solar cell.

\section{INTRODUCTION}

With an increase of wastewater discharge according to the urban development, a significant amount is discharged into local water bodies, resulting in a large accumulation of sediment in the water bodies. High rates of organic matter decomposition in the sediment deteriorate the aquatic environment [1], [2]. Conversely, sediment can be a useful natural resource owing to the presence of organic compounds in them.

Most of the organic compounds present in sediment are in the form of metal complexes. During sedimentation, organic matter absorbs other metal ions or clay minerals (soil particles) to form metal complexes. As a metal complex, organic matter is considered as hardly decomposed organic matter, which is difficult to use as natural resources, such as agriculture fertilizers and bio fuels. Therefore, separating organic matter from metal or clay mineral complexes may provide an improvement for the potential use of sediment.

From the viewpoint of using organic compounds, several methods have been proposed for changing organic

\footnotetext{
Manuscript received July 7, 2017; revised January 23, 2018. This work was supported in part by the Japan Society for the Promotion of Science: Grant-in-Aid for Science Research under the grant No. 16K18158 and $16 \mathrm{H} 04418$.

The authors are with Hiroshima University, Higashihiroshima 739-8527, Japan (e-mail: m175472@hiroshima-u.ac.jp, hibinot@hiroshima-u.ac.jp).
}

compounds into useful products. For instance, Zhang et al. [3] reported that the alkaline treatment involving the addition of steel slag into waste activated sludge provided better performance for both sludge hydrolysis and acidification. The authors revealed that an increase in the production of volatile fatty acid and higher enzyme activities were obtained after the alkaline treatment. Li et al. [4] demonstrated that alkaline post-treatments increased the level of volatile fatty acids and polysaccharides in sludge. Song and Jiang [5] noted that heating the sediment prior to use as a fuel in sediment microbial fuel cells (SMFCs) provided a higher power density of SMFCs. Furthermore, the application of SMFCs into sediment has been shown to alter the organic matter characteristics in the sediment [6], [7].

Our previous studies showed that decreases in the sediment $\mathrm{pH}$ owing to the electron recovery from the sediment could cause the dissociation of calcium and iron complexes. This dissociation leads to the release of ferric ions in the sediment pore water [8] and changes in the ignition characteristics of the sediment [9]. Moreover, the enhancement of sediment remediation and enrichment of microorganisms in the sediment following electron recovery were confirmed [10]. This study aims to understand changes in organic matter characteristics of sediment when a solar cell-combined SMFC (SC-SMFC) is applied into the sediment. Another objective is to understand the effects of applying the method of SC-SMFC on changes in the organic matter characteristics.

\section{MethodS AND MATERIALS}

\section{A. Experimental Device and Materials}

Fig. 1 shows the experimental device used in this study. The device comprised two containers ( $310 \mathrm{~mm}$ in height, 556 $\mathrm{mm}$ in length, and $386 \mathrm{~mm}$ in width). One container was filled with sediment (anode) and a second was filled with tap water (cathode). In the anode container, six sheets of electrode board $(180 \mathrm{~mm} \times 370 \mathrm{~mm})$ were installed at intervals of $100 \mathrm{~mm}$, as shown in Fig. 1. An electrode board comprised a plastic board attached by carbon cloth (News Company, PL200-E) with a surface area of $0.28 \mathrm{~m}^{2}$. Following Nagatsu et al. [11], the carbon cloth was heated to $500^{\circ} \mathrm{C}$ for $1 \mathrm{~h}$ to improve its performance before being used as the electrode material.

After installing the electrode boards, the sediment was placed into the anode container. Tap water was added to the cathode container, and a surface area of $1 \mathrm{~m}^{2}$ of brush type-cathode was installed near the water surface (Fig. 1). 
The heated carbon cloth was broken into fibers to create the brush type-cathode.

The sediment used in the experiments was collected from the riverbank of a tidal river (Eba, Hiroshima, Japan). Approximately $300 \mathrm{~mm}$ of surface sediment was collected from the deposited sediment on the riverbank using a scope. The sediment was placed in clean plastic buckets and transported to the laboratory. Next, the sediment was homogenized by mixing prior to use in the experiments. Pretreatment of the sediment was not conducted before being used in the experiments. The $\mathrm{pH}$ and redox potential (ORP) of the sediment were 7.05 and $-408 \mathrm{mV}$ vs $\mathrm{Ag} / \mathrm{AgCl}$ sat. $\mathrm{KCl}$, respectively. The $\mathrm{pH}$ and ORP were directly measured using a $\mathrm{pH} / \mathrm{ORP}$ meter (Horiba, D-50).

\section{B. System Operation and Sediment Analysis}

The anode and cathode were connected to a solar cell (Tamiya, 1.5 V-500 mA) to increase the electrical current of the system. An external resistance (Fig. 1, R) was loaded between the anode and the solar cell for controlling the system current. The voltage of the two ends of the external resistance was recorded every minute using a voltage logger (Graphtec, GL840-M). The current was calculated using the recorded voltage based on Ohm's law, $I=U / R_{e x}$, where $U(\mathrm{~V})$ is the voltage, $I(\mathrm{~A})$ is the current, and $R_{e x}(\Omega)$ is the external resistance.

Two scenarios of the experiments were performed: i) SC-SMFC was applied to the sediment for the electron recovery only (SC-SMFC-1) and ii) SC-SMFC was also applied to the sediment for the electron recovery, and a small amount of electrons was supplied into the sediment during the course of electron recovery (SC-SMFC-2).

Fig. 2 shows the temporal variations of the current in each SC-SMFC. As it is not possible to fix the system current with the solar cell, the system current varies along with variations of the SMFC performance. In SC-SMFC-1, electrons were removed from the sediment with a stable maximum current of 2.4-3.6 mA. In SC-SMFC-2, electrons were removed from the sediment with a stable maximum current of 2.0-3.6 mA, which was the same order of magnitude as that of SC-SMFC-1. The negative current had a maximum value of $-1.4 \mathrm{~mA}$ in SC-SMFC-2, which refers to the supply of electrons into the sediment. Note that the method of supplying electrons was the same as that of recovering electrons in which the solar cell and an external resistance were used. However, the direction of electron flow was reversed. For SC-SMFC-2, electrons were supplied to abate the sediment acidification due to the electron recovery.

The initial current was set to create an initial anode potential of $200 \mathrm{mV}$ vs. $\mathrm{Ag} / \mathrm{AgCl}$ sat. $\mathrm{KCl}$ based on the results reported by Wang et al. [12] and Touch et al. [8]. These researchers showed that a positive potential of $200 \mathrm{mV}$ could increase the electrochemical activity of the anodic biological community during start-up.

At the end of the experiment, the sediment $\mathrm{pH}$ and ORP were measured by directly inserting the $\mathrm{pH} / \mathrm{ORP}$ meters into the sediment. The sediment was then placed in 50 $\mathrm{mL}$-centrifuge tubes. The tubes were centrifuged at a speed of $6000 \mathrm{rpm}$ for $10 \mathrm{~min}$ to extract the sediment pore water (AS ONE, CN2060). Finally, the concentrations of several major ions, such as hydrogen sulfide $\left(\mathrm{H}_{2} \mathrm{~S}\right)$ and nutrient salts, were measured using a digital water quality analyzer (Kyoritsu Chemical-Check Lab. Corp., 19000).

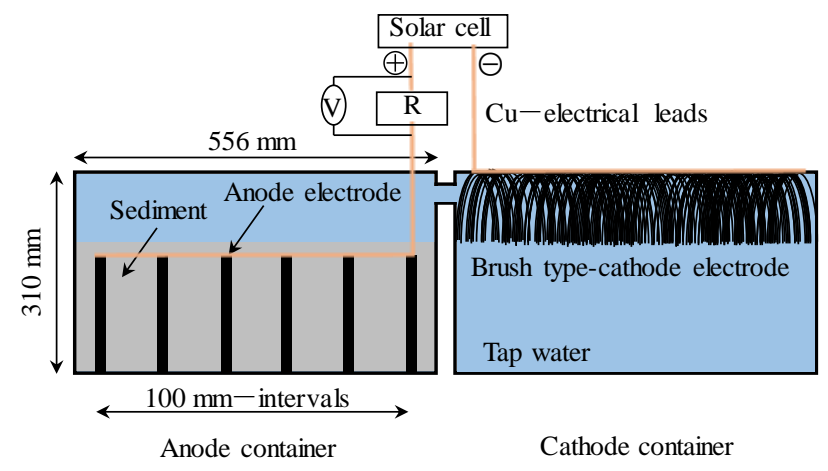

Fig. 1. Experimental device used in the experiments.

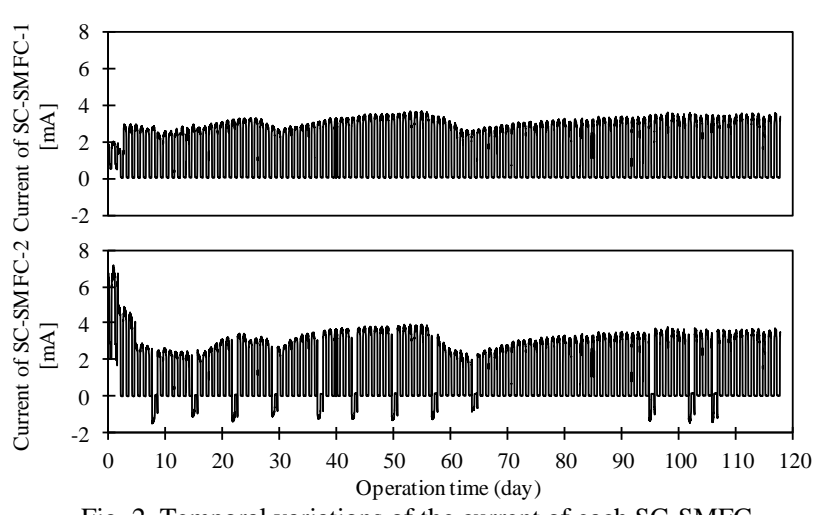

Fig. 2. Temporal variations of the current of each SC-SMFC.

No pretreatment of the sediment pore water was conducted before being used in the analysis. To examine the organic matter characteristics of the sediment, thermogravimetric analysis (TG/DTA) was conducted using a Shimadzu-DTG $60 \mathrm{H}$ analyzer, in which a $30 \mathrm{mg}$ sample of freeze-dried sediment was heated with a scan rate of $5^{\circ} \mathrm{C} / \mathrm{min}$. Furthermore, the FTIR analysis of the freeze-dried sediment was conducted using a Shimadzu IRAffinity-1S (DRS-8000).

\section{RESUlTS AND DISCUSSION}

\section{A. Changes in Redox Conditions ( $p H-O R P$ Relation) by $S C-S M F C$}

Fig. 3 shows the changes in redox conditions after the application of SC-SMFC into the sediments. Based on Fig. 2, approximately $15839 \mathrm{C}$ of electrical charges were recovered from the sediment in SC-SMFC-1, approximately similar to that of SC-SMFC-2 (15305 C). However, approximately 590 $\mathrm{C}$ in total were supplied into the sediment in SC-SMFC-2.

The sediment $\mathrm{pH}$ decreased from 7.30 to 7.02 in SC-SMFC-1 and from 7.39 to 7.11 in SC-SMFC-2. Although the decreases in the sediment $\mathrm{pH}$ were the same between SC-SMFC-1 and SC-SMFC-2, the sediment $\mathrm{pH}$ of SC-SMFC-2 remained higher than that of SC-SMFC-1. Furthermore, the increases in the sediment ORP were different between SC-SMFC-1 and SC-SMFC-2. The sediment ORP increased from -357 to $-333 \mathrm{mV}$ in SC-SMFC-1 and from -397 to $-325 \mathrm{mV}$ in SC-SMFC-2. A larger increase in the sediment ORP was found in 
SC-SMFC-2. Consequently, the increasing gradient of the sediment ORP against $\mathrm{pH}$ in SC-SMFC-2 was larger than that in SC-SMFC-1 (Fig. 3).

Protons are released during the oxidation of reduced substances (e.g., $\mathrm{H}_{2} \mathrm{~S}$ and $\mathrm{Fe}^{2+}$ ) and organic matter at the anode (e.g., Eqs. 1-3) [13]. As other cations have a higher concentration than the proton concentration in the sediment, the proton diffusion from the sediment into overlying water is limited [14], leading to a decrease in the sediment $\mathrm{pH}$. According to the Nernst equation, ORP relates to the ratio of oxidants to reductants (i.e., reduced substances), which increases with an increase in the concentration of oxidants. Therefore, the oxidation of reduced substances at the anode causes an increase of oxidants, leading to the increase in the sediment ORP.

$$
\begin{aligned}
& \mathrm{C}_{2} \mathrm{H}_{4} \mathrm{O}_{2}+2 \mathrm{H}_{2} \mathrm{O} \Rightarrow 2 \mathrm{CO}_{2}+8 \mathrm{H}^{+}+8 \mathrm{e}^{-} \\
& \mathrm{H}_{2} \mathrm{~S}+4 \mathrm{H}_{2} \mathrm{O} \Rightarrow \mathrm{SO}_{4}{ }^{2-}+10 \mathrm{H}^{+}+8 \mathrm{e}^{-} \\
& \mathrm{Fe}^{2+}+3 \mathrm{H}_{2} \mathrm{O} \Rightarrow \mathrm{Fe}(\mathrm{OH})_{3}+3 \mathrm{H}^{+}+\mathrm{e}^{-}
\end{aligned}
$$

It is important to note the different gradient of $\mathrm{pH}-\mathrm{ORP}$ relation between SC-SMFC-1 and SC-SMFC-2. As seen in Eqs. (2) and (3), different oxidation reactions release different amounts of protons. Hence, the different gradient of $\mathrm{pH}-\mathrm{ORP}$ relation ensures that the oxidation reactions in SC-SMFC-1 differ from those in SC-SMFC-2. Briefly, different redox conditions of sediment can be obtained by changing the method of applying SC-SMFC into the sediment. As the redox conditions differ, it is expected that changes in sediment quality differ between SC-SMFC-1 and SC-SMFC-2.

\section{B. Dissociation of Metal Complexes in Sediment by $S C-S M F C$}

In previous studies [8], [9], it was observed that the electron recovery from sediment caused the dissociation of metal complexes, resulting in an increase in the concentration of ferric ions in the sediment pore water. Therefore, the dissociation of metal complexes can be understood based on variations in the concentration of metal ions in the sediment pore water.

Fig. 4 depicts the changes in the concentration of metal ions in the sediment pore water after the application of SC-SMFC. In this study, it was also observed that the concentration of total iron ion (Fe) increased in the sediment in which SC-SMFC was applied. Compared with the control sediment, Fe concentration increased from 0.13 to $0.45 \mathrm{mg} / \mathrm{L}$ in SC-SMFC-1 and from 0.16 to $0.36 \mathrm{mg} / \mathrm{L}$ in SC-SMFC-2. A similar trend was noted for the concentration of other metal ions such as $\mathrm{Na}^{+}, \mathrm{Ca}^{2+}$, and $\mathrm{K}^{+}$. In SC-SMFC-1, $\mathrm{Na}^{+}, \mathrm{Ca}^{2+}$, and $\mathrm{K}^{+}$concentrations increased from 3500 to $3900 \mathrm{mg} / \mathrm{L}$, 130 to $150 \mathrm{mg} / \mathrm{L}$, and 130 to $140 \mathrm{mg} / \mathrm{L}$, respectively. In SC-SMFC-2, $\mathrm{Na}^{+}, \mathrm{Ca}^{2+}$, and $\mathrm{K}^{+}$concentrations increased from 2600 to $2800 \mathrm{mg} / \mathrm{L}, 89$ to $130 \mathrm{mg} / \mathrm{L}$, and 105 to 110 $\mathrm{mg} / \mathrm{L}$, respectively. As these ions were not supplied to the sediments during the reactions, it is likely that the dissociation of metal complexes occurred owing to the application of SC-SMFC, which is in good agreement with previous studies [8], [9].

The dissociation may be caused partly due to the decrease in sediment $\mathrm{pH}$. During sedimentation, organic matter or other ions adsorb onto each other as complex molecules and are deposited as the sediment [15]. The stability of a complex molecule depends on $\mathrm{pH}$, in which a decrease in $\mathrm{pH}$ makes a complex unstable and leads to its dissociation [16]. Hence, the decreasing $\mathrm{pH}$ resulting from the SC-SMFC application is considered to cause the dissociation of metal complexes.

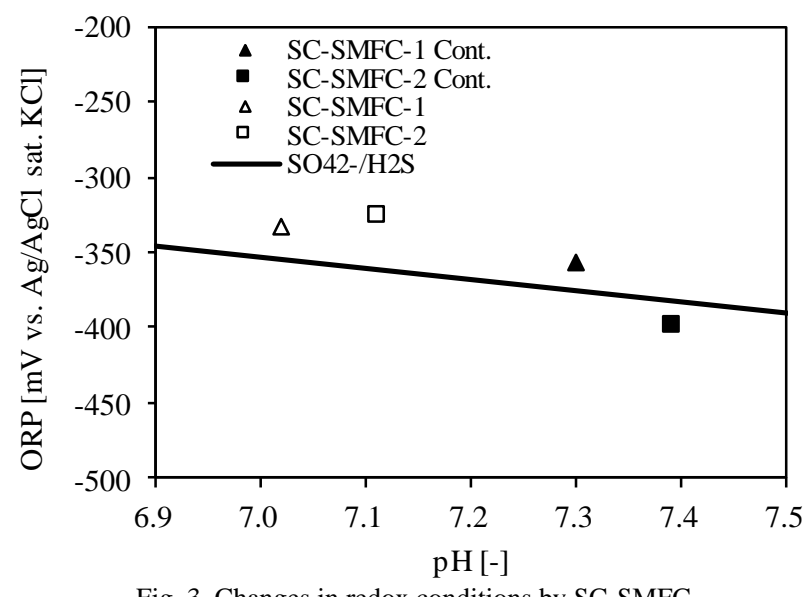

Fig. 3. Changes in redox conditions by SC-SMFC.
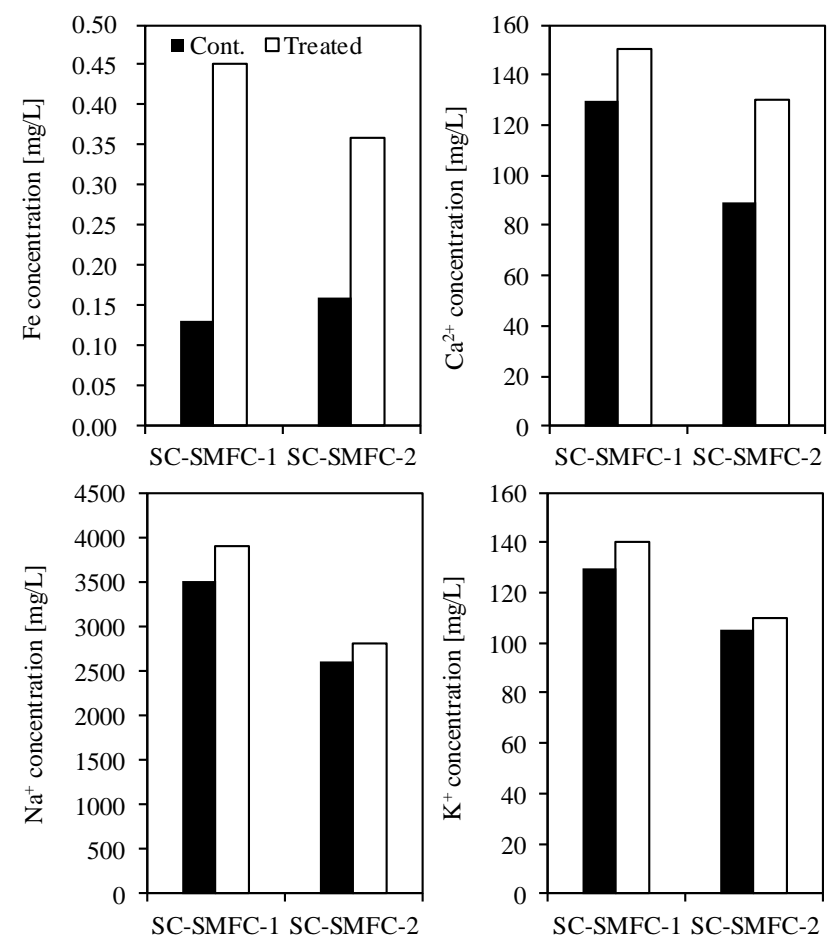

Fig. 4. Changes in the concentration of metal ions in the sediment pore water by SC-SMFC.

Interestingly, the increase in the concentration of metal ions in SC-SMFC-1 was larger than that in SC-SMFC-2, except the $\mathrm{Ca}^{2+}$ concentration. This result showed that supplying electrons into sediment may cause re-adsorption of the dissociated ions. As noted earlier, the stability of a complex molecule depends on $\mathrm{pH}$. Because reduction reactions at the anode occurred during the supply of electrons into the sediment, hydroxyl ions are released during the reactions that cause an increase in the sediment $\mathrm{pH}$. This increase in the sediment $\mathrm{pH}$ may induce the re-adsorption of the dissociated ions. Therefore, only electron recovery from 
sediment should be conducted for effectively dissociating metal complexes in the sediment.

\section{Changes in the Concentration of Nutrient Salts in the Sediment Pore Water}

As nutrient salts are released during anaerobic decomposition processes of organic matter [17], the organic matter decomposition can be understood based on variations in the concentration of nutrient salts. Furthermore, the ignition characteristics and FTIR spectra of organic matter vary owing to changes in the state of organic matter during decomposition [18], [19]. In the case of the SMFC application (i.e., the electron recovery from sediment), Touch et al. [20] confirmed decreases in ammonium $\left(\mathrm{NH}_{4}{ }^{+}\right)$and phosphate $\left(\mathrm{PO}_{4}{ }^{3-}\right)$ concentrations in the sediment pore water. The authors also noted that the decrease of $\mathrm{NH}_{4}^{+}$was due to the anode activities. In addition, the metal ions from the dissociated metal complexes fixed $\mathrm{PO}_{4}{ }^{3-}$, leading to a decrease in $\mathrm{PO}_{4}{ }^{3-}$ in the sediment pore water.

Fig. 5 depicts the changes in the concentrations of $\mathrm{NH}_{4}^{+}$ and $\mathrm{PO}_{4}{ }^{3-}$ ions in the sediment pore water after the application of SC-SMFC. In SC-SMFC-1, $\mathrm{NH}_{4}{ }^{+}$and $\mathrm{PO}_{4}{ }^{3-}$ concentrations decreased from 26.9 to $10.4 \mathrm{mg} / \mathrm{L}$ and from 12.9 to $2.3 \mathrm{mg} / \mathrm{L}$, respectively. These are in good agreement with the suggestions by Touch et al. [20]. Interestingly, in SC-SMFC-2, $\mathrm{PO}_{4}{ }^{3-}$ concentration decreased from 14.9 to $11.9 \mathrm{mg} / \mathrm{L}$, whereas $\mathrm{NH}_{4}{ }^{+}$concentration increased from 33.0 to $33.8 \mathrm{mg} / \mathrm{L}$. The decrease in $\mathrm{NH}_{4}{ }^{+}$concentration was not observed and only a small decrease in $\mathrm{PO}_{4}{ }^{3-}$ concentration was observed compared with those in SC-SMFC-1.

This is likely due to a large release of nutrient salts occurring in SC-SMFC-2, which indicates that the decomposition processes of organic matter in SC-SMFC-2 differ from those in SC-SMFC-1. The decomposition of organic matter in SC-SMFC-2 was enhanced, leading to a larger release of $\mathrm{NH}_{4}{ }^{+}$and $\mathrm{PO}_{4}{ }^{3-}$ in the sediment. As discussed earlier, the variations in redox conditions ( $\mathrm{pH}-\mathrm{ORP}$ relation in Fig. 3) were different between SC-SMFC-1 and SMFC-2. This difference in redox conditions may induce the differing decomposition processes of organic matter because the decomposition of organic matter strongly depends on the redox conditions.

\section{Changes in the Organic Matter Characteristics of Sediment by SC-SMFC}

From the variations in the concentration of nutrient salts, the decomposition processes of organic matter between SC-SMFC-1 and SC-SMFC-2 were predicted to be different. This may result in different organic matter characteristics of the sediment in SC-SMFC-1 and SC-SMFC-2. To provide a better understanding of the organic matter characteristics, the ignition characteristics (DTA) and FTIR spectra of each sediment were examined, as shown in Figs. 6 and 7, respectively.

As heat is released during the combustion of organic matter, a decrease in DTA is assumed as the loss of organic matter. From the DTA results (Fig. 6), in comparison with the control sediment, DTA of SC-SMFC-1 increased in the temperature range of $200-650^{\circ} \mathrm{C}$ and decreased in the temperature range of $650-800^{\circ} \mathrm{C}$. DTA of SC-SMFC-2 decreased compared with that of the control sediment. As organic matter burns below $600^{\circ} \mathrm{C}[21]$, it can be concluded that the amount of organic matter increased in SC-SMFC-1, whereas it decreased in SC-SMFC-2.
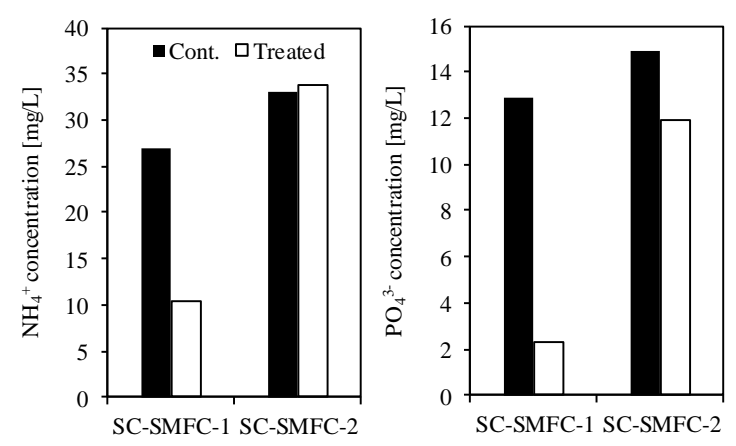

Fig. 5. Changes in the concentrations of ammonium $\left(\mathrm{NH}_{4}^{+}\right)$and phosphate $\left(\mathrm{PO}_{4}{ }^{3-}\right)$ ions in the sediment pore water by SC-SMFC.

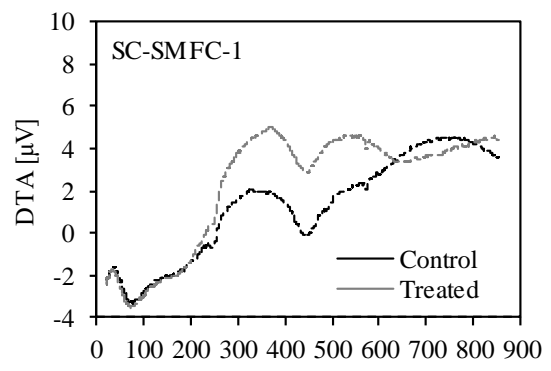

Ignition temperature $\left[{ }^{\circ} \mathrm{C}\right]$

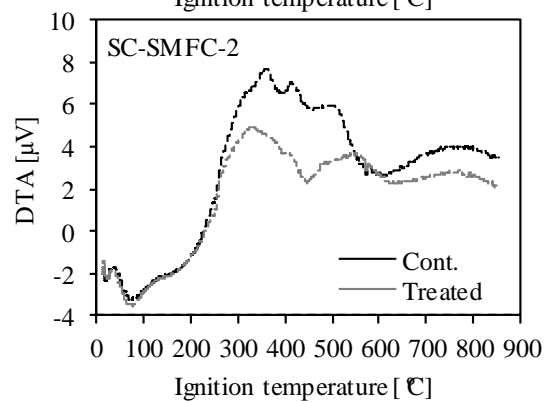

Fig. 6. Changes in DTA of thermal analysis after the application of SC-SMFC.

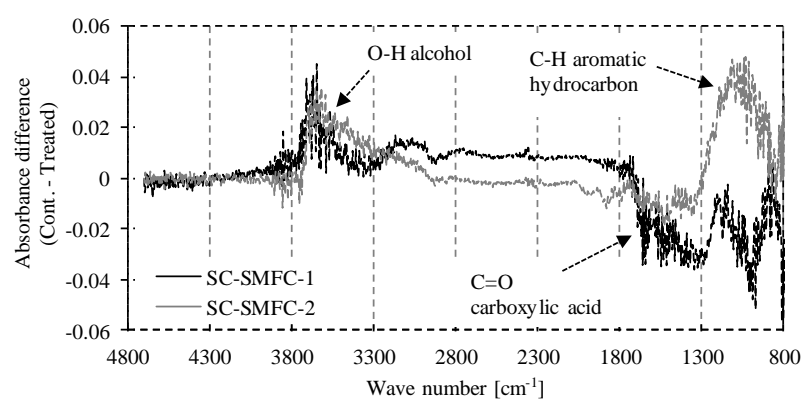

Fig. 7. Changes in FTIR spectra after the application of SC-SMFC.

Since there was no re-supply of organic matter into the sediment and the concentration of metal ions in the sediment pore water increased (Fig. 4), the increasing amount of organic matter in SC-SMFC-1 may result from the dissociation of organic matter from metal complexes. For SC-SMFC-2, the decreasing amount of organic matter may be partly due to the enhancement in the decomposition of dissociated organic matter according to the supply of electrons into the sediment. The important conclusion from these results is that the supply of electrons into sediment plays a major role in enhancing organic matter decomposition in sediment. 
The enhancement of organic matter decomposition was also observed in the FTIR spectra (Fig. 7). In Fig. 7, a positive value refers to the loss of substances from the control sediment. The absorbance significantly increased (positive) in the wave number of $2900-3800 \mathrm{~cm}^{-1}$, and decreased (negative) in the wave number of $1300-1800 \mathrm{~cm}^{-1}$ in both SC-SMFC-1 and SC-SMFC-2. These indicate decreases in $\mathrm{O}-\mathrm{H}$ alcohol substances and increases in $\mathrm{C}=\mathrm{O}$ carboxylic acids in both sediments due to the application of SC-SMFC.

The variation of the absorbance in the wave number range of $800-1300 \mathrm{~cm}^{-1}$ (C-H aromatic hydrocarbon) should be noted. The absorbance decreased (negative) in SC-SMFC-1, indicating the formation of $\mathrm{C}-\mathrm{H}$ aromatic hydrocarbons. Conversely, the absorbance increased (positive) in SC-SMFC-2, indicating the decomposition of $\mathrm{C}-\mathrm{H}$ aromatic hydrocarbons. These results confirmed that the decomposition processes of organic matter in SC-SMFC-2 differed from those in SC-SMFC-1. The decomposition of organic matter in SC-SMFC-2 was facilitated compared with that in SC-SMFC-1, which is consistent with the suggestion from the variations of nutrient salts (Fig. 5) and DTA (Fig. 6). This further establishes that the supply of electrons into the sediment plays an important role in the decomposition processes of organic matter.

\section{CONCLUSIONS}

Laboratory experiments were conducted to examine changes in the organic matter characteristics of littoral sediment when SC-SMFC was applied into the sediment. It was observed that the electron recovery from the sediment was an effective method for dissociating metal complexes, leading to the release of useful metal ions and a change in the organic matter characteristics of the sediment. During electron recovery, a small amount of electrons was supplied into the sediment, which played an important role in the decomposition of organic matter. It can be concluded that the combination of electron recovery from sediment with a small amount of electron supply can enhance the organic matter decomposition in the sediment.

\section{ACKNOWLEDGMENT}

The authors gratefully acknowledge partial funding from the Japan Society for the Promotion of Science: Grant-in-Aid for Science Research under the grant No. 16K18158 and 16H04418. The constructive comments of anonymous reviewers are also appreciated.

\section{REFERENCES}

[1] W. R. Martin, "Chemical processes in estuarine sediments," Encycl Ocean Sci., Elsevier, pp. 539-550, 2009.

[2] J. J. Wright, K. M. Konwar, and S. J. Hallam, "Microbial ecology of expanding oxygen minimum zones," Nat. Rev. Microbiol., vol. 10, pp. 381-394, 2012 .

[3] Y. Zhang, C. Zhang, X. Zhang, L. Feng, Y. Li, and Q. Zhou, "Waste activated sludge hydrolysis and acidification: A comparison between sodium hydroxide and steel slag addition," J. Environ. Sci., vol. 48, pp. 200-208, 2016

[4] H. Li, S. Zou, C. Li, and Y. Jin, "Alkaline post-treatment for improved sludge anaerobic digestion," Bioresour. Technol., vol. 140, pp. 187-191, 2013
[5] T. S. Song and H. L. Jiang, "Effects of sediment pretreatment on the performance of sediment microbial fuel cells," Bioresour. Technol., vol. 102, pp. 10465-10470, 2011

[6] S. W. Hong, H. S. Kim, and T. H. Chung, "Alteration of sediment organic matter in sediment microbial fuel cells," Environ. Pollut., vol 158, pp. 185-191, 2010.

[7] N. Touch, T. Hibino. Y. Nagatsu, and K. Tachiuchi, "Characteristics of electricity generation and biodegradation in tidal river sludge-used microbial fuel cells," Bioresour. Technol., vol. 158, pp. 225-230, 2014

[8] N. Touch, N. Kinjo, K. Tachiuchi, S. Nakashita, and T. Hibino, "Development of a method for improving reduced environment of the sludge deposited in estuarine regions," J. Jpn. Soc. Civ. Eng. Ser. B1 (Hydraul. Eng.), vol. 71, pp. 697-702, 2015. in Japanese

[9] N. Touch, N. Kinjo, T. Hibino, and H. Takata, "Effects of electron recovery from sediment on sediment and water environments," in Proc. 2017 SICEAS Conf., 2017, pp. 46-57, 2017.

[10] N. Touch, T. Hibino, S. Nakashita, and K. Nakamoto, "Variation in properties of the sediment following electrokinetic treatments," Environ. Technol., vol. 38, no. 3, pp.277-284, 2017

[11] Y. Nagatsu, K. Tachiuchi, N. Touch, and T. Hibino, "Factors for improving the performance of sediment microbial fuel cell," J. Jpn. Soc. Civ. Eng. Ser. B2 (Coast. Eng.), vol. 70, no. 2, pp. 1066-1070, 2014

[12] X. Wang, Y. Feng, N. Ren, H. Wang, H. Lee, N. Li, and Q. Zhoa, "Accelerated start-up of two-chambered microbial fuel cells: Effect of anodic positive poised potential," Electrochem. Acta, vol. 54, no. 3, pp. 1109-1114, 2009.

[13] B. E. Logan, B. Hamelers, R. Rozendal, U. Schroder, J. Keller, S. Freguia, P. Aelterman, W. Verstraete, and K. Rabaey, "Microbial fuel cells: methodology and technology." Environ. Sci. Technol., vol. 40, pp. 5181-5192, 2006.

[14] R. A. Rozendal, H. V. M. Hamelers, and C. J. N. Buisman, "Effects of membrane cation transport on $\mathrm{pH}$ and microbial fuel cell performance," Environ. Sci. Technol., vol. 40, pp. 5206-5211, 2006.

[15] A. Matilainen, M. Vepsäläinen, and M. Sillanpää, "Natural organic matter removal by coagulation during drinking water treatment: A review," Adv. Colloid Interface Sci., vol. 159, pp. 189-197, 2010.

[16] S. Tahervand and M. Jalali, "Sorption and desorption of potentially toxic metals $(\mathrm{Cd}, \mathrm{Cu}, \mathrm{Ni}$ and $\mathrm{Zn})$ by soil amended with bentonite, calcite and zeolite as a function of pH," J. Geochem. Explor., vol. 181, pp. 148-159, 2017.

[17] J. W. M. Wijsman, P. M. J. Herman, J. J. Middelburg, and K. Soetaert, "A model for early diagenetic processes in sediments of the continental shelf of the Black Sea," Estuar. Coast. Shelf Sci., vol. 54, pp. 403-421, 2002.

[18] C. Cuypers, T. Grotenhuis, K. G. Nierop, E. M. Franco, A. Jager, and W. Rulkens, "Amorphous and condensed organic matter domains: the effect of persulfate oxidation on the composition of soil/sediment organic matter," Chemosphere, vol. 48, pp. 919-931, 2002.

[19] B. Gu, J. Schmitt, Z. Chen, L. Liang, and J. F. McCarthy, "Adsorption and desorption of different organic matter fractions on iron oxide," Geochim. Cosmochim. Acta, vol. 59, no. 2, pp. 219-229, 1995.

[20] N. Touch, N. Kinjo, T. Hibino, and K. Nakamoto, "Effective used of granulated coal ash in sediment microbial fuel cells," J. Jpn. Soc. Civ. Eng. Ser. B2 (Coast. Eng.), vol. 72, no. 2, pp. 1327-1332, 2016.

[21] T. Hibino, K. Tachiuchi, N. Touch, and S. Nakashita, "Classification of organic matter existing in littoral sediments," J. Jpn. Soc. Civ. Eng. Ser. B2 (Coast. Eng.), vol. 70, no. 2, pp. 1101-1105, 2014.

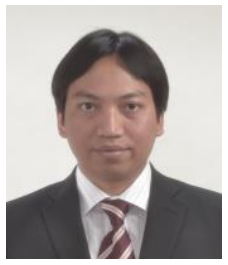

Narong Touch is an assistant professor at Hiroshima University (Japan). He received his doctor degree in engineering from Hiroshima University in 201. He was a research fellowship for Young Scientists of Japan Society for the Promotion of Science during 2010-2013.

$\mathrm{He}$ has been involved in the development and application of environmental materials for water purification and sediment remediation. His other research interests are resource recovery, and developing electrochemistry technologies for sediment and wastewater treatments.

$\mathrm{He}$ is a member of Japan Society of Civil Engineers, and a reviewer of international journals. He has been granted many awards from international conference communities, Hiroshima University, Japan Society of Civil Engineers, and the mayor of Osaka City (Osaka, Japan). 